\title{
Dibenzylbutyrolactone Lignans from Forsythia koreana Fruits Attenuate Lipopolysaccharide-Induced Inducible Nitric Oxide Synthetase and Cyclooxygenase-2 Expressions through Activation of Nuclear Factor- $\kappa \mathrm{B}$ and Mitogen-Activated Protein Kinase in RAW264.7 Cells
}

\author{
Ji Yun Lee, Bong Jae Cho, Tae Wook PArk, Byoung Eun Park, Soo Jung KIM, Sang Soo Sim, and \\ Chang Jong KIM* \\ Division of Pathophysiology and Pharmacology, College of Pharmacy, Chung-Ang University; 221 Huksuk-dong, \\ Dongjak-ku, Seoul 156-756, Korea. Received April 19, 2010; accepted August 18, 2010
}

\begin{abstract}
Previously, we reported that dibenzylbutyrolactone lignans (DBLLs) from the fruit of Forsythia koreana NAKAI (Oleaceae) has anti-inflammatory, antioxidant, and anti-asthmatic effects. In this study, to clarify the antiinflammatory mechanisms of DBLL, we evaluated the effects of DBLLs on lipopolysaccharide-stimulated inducible nitric oxide synthetase (iNOS) and cyclooxygenase-2 (COX-2) expressions, nitric oxide (NO) and prostaglandin $\mathrm{E}_{2}\left(\mathrm{PGE}_{2}\right)$ productions, nuclear factor- $\kappa \mathrm{B}(\mathrm{NF}-\kappa \mathrm{B})$ and mitogen-activated protein kinase (MAPK) activations, inhibitor of $\kappa \mathrm{B}(\mathrm{I} \kappa \mathrm{B})$ and inhibitor of $\kappa \mathrm{B}$ kinase (IKK) phosphorylations in cytosolic proteins, and cytotoxicity in Raw264.7 cells. DBLLs potently suppressed both the enzyme expression and DNA-binding activity of NF- $\kappa \mathrm{B}$. Arctiin, arctigenin $\left(1.0 \mu_{\mathrm{M}}\right)$ and matairesinol $\left(10 \mu_{\mathrm{M}}\right)$ inhibited the expression of iNOS by $37.71 \pm$ $2.86 \%, 32.51 \pm 4.28 \%$, and $27.44 \pm 2.65 \%$, respectively, and arctiin, arctigenin $(0.1 \mu \mathrm{M})$ and matairesinol $(1.0 \mu \mathrm{M})$ inhibited COX-2 expression by $37.93 \pm 7.81 \%, 26.70 \pm 4.61 \%$ and $29.37 \pm 5.21 \%$, respectively. The inhibitory effects of DBLLs on NO and $\mathrm{PGE}_{2}$ productions were the same patterns as those seen for the reductions in iNOS and COX-2 expression, respectively. Arctiin, arctigenin $\left(1.0 \mu_{\mathrm{M}}\right)$ and matairesinol $\left(10 \mu_{\mathrm{M}}\right)$ significantly $(p<0.05)$ inhibited NF- $\kappa$ B DNA binding by $44.85 \pm 6.67 \%, 44.16 \pm 6.61 \%$, and $44.79 \pm 5.62 \%$, respectively, and arctiin $\left(0.1 \mu_{\mathrm{M}}\right)$ and arctigenin $\left(1.0 \mu_{\mathrm{M}}\right)$ significantly $(p<0.05)$ inhibited the phosphorylation of $\mathrm{I} \kappa \mathrm{B}$ by $20.58 \pm 3.86 \%$ and $25.99 \pm 6.18 \%$, respectively. Furthermore, arctiin, matairesinol $\left(1.0 \mu_{\mathrm{M}}\right)$ and arctigenin $(10 \mu \mathrm{M})$ inhibited the phosphorylation of IKK by $38.80 \pm 6.64 \%, 38.33 \pm 6.65 \%$, and $38.57 \pm 8.14 \%$, respectively. In addition, DBLLs

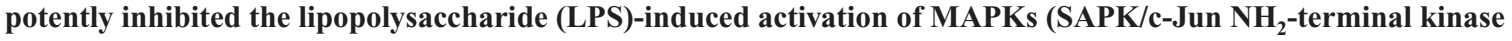
(JNK), p38, and extracellular signal receptor-activated kinase (ERK)1/2). Overall, arctiin was the most effective; its effect was nearly the same as that of $10 \mu_{\mathrm{M}}$ helenalin. These findings suggest that treatment with non-toxic DBLLs inhibits not only NF- $\kappa \mathrm{B}$ and NF- $\kappa \mathrm{B}$-regulated protein activation, but also potently inhibits the activations of specific MAPKs.
\end{abstract}

Key words lignan; nuclear factor- $\kappa \mathrm{B}$; inducible nitric oxide synthetase; cyclooxygenase

In a previous study, we reported that phenylpropanoid dibenzylbutyrolactone lignans (DBLLs) isolated from Forsythiae Fructus exhibited anti-inflammatory, antioxidant, analgesic $^{1)}$ and anti-asthmatic effects ${ }^{2)}$ in experimental animal models. A large number of naturally occurring compounds, such as lignans, sesquiterpernes, diterpens, triterpenes, and polypenols, are thought to be possible inhibitors of the nuclear factor- $\kappa \mathrm{B}$ (NF- $\kappa \mathrm{B})$ pathway. ${ }^{3)}$ Forsythiae Fructus, the dried fruits of Forsythia koreana NAKAI, Forsythia viridissima LINDLE, and Forsythia suspense VAHL (Oleaceae), have long been used in Chinese medicine as therapeutic agents for the treatment of infectious and inflammatory disorders. ${ }^{4)}$ Previous chemical studies of these DBLLcontaining plant materials have reported the presence of biological activity as well as anti-inflammatory and antitumor activities. ${ }^{47}$ However, the effects of these DBLLs on the $\mathrm{NF}-\kappa \mathrm{B}$ signaling pathway are still poorly understood.

$\mathrm{NF}-\kappa \mathrm{B}$ is one of the most important transcription factors, controlling the gene expressions of cytokines, chemokines, growth factors, cell adhesion molecules, and acute phase proteins in both healthy and disease states. ${ }^{8)}$ The transcription factor NF- $\kappa \mathrm{B}$ can be activated by extracellular stimuli, such as Pseudomonas aeruginosa lipopolysaccharide (LPS), tumor-necrosis factor- $\alpha$ (TNF- $\alpha$ ), and other pro-inflammatory mediators. This activation subsequently promotes the transcription of a number of genes involved in inflammation, including inducible nitric oxide synthetase (iNOS), cyclooxygenase-2 (COX-2), and specific cytokines. ${ }^{9)}$ LPS-activated macrophages play an important role in inflammatory disease by producing pro-inflammatory cytokines and other inflammatory mediators such as nitric oxide (NO) and prostaglandin $\mathrm{E}_{2}\left(\mathrm{PGE}_{2}\right) \cdot{ }^{10,11)} \mathrm{NO}$ and $\mathrm{PGE}_{2}$ productions are regulated by NO synthase and cyclooxgenases, respectively; therefore, over-production of NO may provide a measure for assessing the effects of drugs on the inflammatory process.

Improper activation or upregulation of NF- $\kappa \mathrm{B}$ or mitogenactivated protein kinase (MAPKs) has been shown to be associated with the pathophysiologic mechanisms of certain types of human cancer ${ }^{12)}$ and inflammatory disorders. ${ }^{13)}$ Therefore, the identification of natural compounds that can suppress or downregulate the activations of NF- $\kappa \mathrm{B}$ and MAPKs may lead to the development of important antiinflammatory therapeutics.

To clarify the mechanisms underlying the anti-inflammatory effects of the DBLLs, arctigenin, arctiin, and matairesionol, we investigated their effects on the expressions of iNOS and COX-2, the productions of $\mathrm{NO}, \mathrm{PGE}_{2}$, and the activations of NF- $\kappa \mathrm{B}$ and MAPKs as well as on the phosphorylations of inhibitor of $\kappa \mathrm{B}(\mathrm{I} \kappa \mathrm{B})$ and inhibitor of $\kappa \mathrm{B}$ kinase (IKK) in LPS-stimulated RAW264.7 macrophage cells using 
electrophoretic mobility shift assay (EMSA) and Western blot analysis. The effects of DBLLs on NF- $\kappa$ B activation were compared with those of helenalin, a specific inhibitor of NF- $\kappa$ B. ${ }^{14)}$ The effects of DBLLs on the activation of MAPKs were compared with those of three specific inhibitors of MAPKs: SP600125, SB203580, and PD98059. ${ }^{15-17)}$

\section{MATERIALS AND METHODS}

Reagents Dulbecco's modified Eagle's medium (DMEM) and fetal bovine serum (FBS) were purchased from Gibco Life Technologies (Rockville, MD, U.S.A.). The WESTone $^{\mathrm{TM}}$ Western Blot Detection System (16032) was obtained from Intron Biotechnology (Kyungki, Korea). Anti-IKK $\alpha$ (2685), anti-phospho-IKK $\alpha / \beta$ (2697S), anti-I $\kappa \mathrm{B} \alpha$ (4812), anti-phospho-I $\kappa \mathrm{B} \alpha(2859 \mathrm{~S})$, anti-c-Jun $\mathrm{NH}_{2}$-terminal kinase (JNK) (4672), anti-phospho-SAPK/JNK (4671), anti-p44/42 MAPK (4695), anti-phospho-p44/42 MAPK (4377), anti-p38 (9212), anti-phospho-p38 MAPK (9215), and anti-rabbit immunoglobulin $\mathrm{G}$ (IgG) horse-radish peroxidase (HRP)linked (7074) antibodies were obtained from Cell Signaling (Danver, MA, U.S.A.). Anti-COX-2 (06-971) antibodies were obtained from Upstate Biotechnology (Lake Placid, NY, U.S.A.). Anti-iNOS (sc-649) antibodies were obtained from Santa Cruz Biotechnology (Santa Cruz, CA, U.S.A.). SP600125 (EI-305), PD98059 (EI-360), and SB203580 (EI286) were obtained from Biomol (Plymouth Meeting, PA, U.S.A.). Helenalin (ALX-350-120-MC05) was obtained from Alexis Biochemicals (Lausen, Switzerland). Nuclear extraction (AY2002) and NF- $\kappa$ B EMSA (AY1030) kits were obtained from Panomics (Fremont, CA, U.S.A.). The bicinchoninic acid (BCA) protein assay kit was obtained from Pierce (Rockford, IL, U.S.A.). 3-(4,5-Dimethylthiazol-2-yl)2,5-diphenyltetrazolium bromide (MTT) reagent was obtained from R\&D Systems (Abington, U.K.). Enzymes and other chemicals were obtained from Sigma Aldrich (St. Louis, MO, U.S.A.).

Plant Materials DBLLs were isolated from the dried fruit of $F$. koreana NAKAI (Oleaceae). The isolated compounds were identified as arctigenin, matairesinol, and arctiin (Fig. 1) through comparison of their phytochemical and spectroscopic data ${ }^{4,18-21)}$ with those of previous reports. The chemical purities of the arctigenin, matairesinol, and arctiin used in this experiment were 98.8, 96.8, and 99.4\%, respectively. A voucher specimen (no. FVL/Fruit/Lignan/01-001003/2007) has been submitted to the College of Pharmacy,
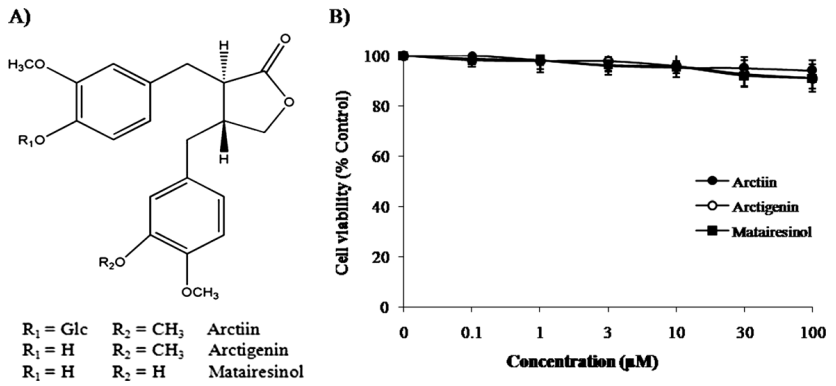

Fig. 1. Chemical Structures of DBLLs (A) and Cytotoxicity in RAW264.7 Cells (B)

Cells were incubated in the presence of $0.1,1,10$, and $100 \mu_{\mathrm{M}}$ DBLL. Cell viability was assessed using the MTT assay. Data represent the mean \pm S.D. of four different samples.
Chung-Ang University. The solution was prepared by dissolving pure DBLL in dimethylsulfoxide (DMSO) diluted with DMEM media. The final concentration of DMSO was adjusted to $0.1 \%(\mathrm{v} / \mathrm{v})$ in the culture media. Control experiments showed that DMSO had no effect on the experiments at this concentration.

Cell Culture RAW264.7 cells from a murine macrophage cell line were obtained from American Type Culture Collection (ATCC, Manassas, VA, U.S.A.) and were cultured as recommended by ATCC, at $37^{\circ} \mathrm{C}$ in DMEM supplemented with $10 \%$ FBS and antibiotics $(100 \mathrm{U} / \mathrm{ml}$ penicillin $\mathrm{G}$, $100 \mu \mathrm{g} / \mathrm{ml}$ streptomycin) in a $5 \% \mathrm{CO}_{2}$ incubator. Cells between passages 5 and 20 were used for experiments at a density of $1 \times 10^{6}$ cells $/ \mathrm{ml}$.

Measurement of Cell Viability Cell viability was assessed using the MTT assay. ${ }^{21)}$ RAW264.7 cells were seeded in a 96-well plate at a density of $5 \times 10^{5} \mathrm{cell} / \mathrm{ml}$ and were treated with various concentrations of DBLLs for $24 \mathrm{~h}$. MTT (final concentration of $200 \mu \mathrm{g} / \mathrm{ml}$ ) was added and incubated for another $4 \mathrm{~h}$ at $37^{\circ} \mathrm{C}$. The culture medium was removed, and cells were dissolved in $0.04 \mathrm{~N} \mathrm{HCl}$ /isopropyl alcohol. The absorbance of each group at a wavelength of $570 \mathrm{~nm}$ was measured using a microplate reader. The control group consisted of untreated cells and was assumed to contain $100 \%$ viable cells.

Measurement of Nitric Oxide Raw cells were pre-incubated at $37^{\circ} \mathrm{C}$ for $12 \mathrm{~h}$ in serum-free medium. NO production was monitored by measuring nitrite levels in the culture media using Greiss reagent (1\% sulfanilamide, $0.1 \% \mathrm{~N}-1$ naphthylenediamine dihydrochloride, and $2.5 \%$ phosphoric acid). Absorbance was measured at $570 \mathrm{~nm}$ using a microplate reader.

Determination of $\mathbf{P G E}_{2}$ Production $\mathrm{PGE}_{2}$ production was measured in cell culture supernatants with an EIA kit according to the manufacturer's instructions.

Nuclear Protein Extraction Cells were pre-incubated with various concentrations of DBLLs for $2 \mathrm{~h}$, then stimulated with LPS $(1.0 \mu \mathrm{g} / \mathrm{ml})$ at $37^{\circ} \mathrm{C}$ for $1 \mathrm{~h}$. Nuclear proteins from the cells were then obtained using a Nuclear Extraction kit (Panomics) according to the manufacturer's instructions. Briefly, following cell activation over the indicated time course, the cells were homogenized in a homogenizer (ArtMiccra, Mullheim). Next, $0.5 \mathrm{ml}$ buffer A (10 mM $N$-(2-hydroxyethyl)piperazine- $N^{\prime}$-2-ethanesulfonic acid (HEPES), $\mathrm{pH} 7.9,10 \mathrm{~mm} \mathrm{KCl}, 10 \mathrm{~mm}$ ethylenediaminetetraacetic acid (EDTA), $10 \mathrm{~mm}$ dithiothreitol (DTT), and protease inhibitor cocktail) was added and incubated on ice for $15 \mathrm{~min}$. After centrifugation at $1000 \times \boldsymbol{g}$ for $10 \mathrm{~min}$, the pellets were resuspended in $0.5 \mathrm{ml}$ buffer A and centrifuged at $15000 \times \boldsymbol{g}$ for $3 \mathrm{~min}$. The pellets were resuspended in $100 \mu \mathrm{l}$ buffer B (10 mм HEPES, pH 7.9, 0.2 M NaCl, 0.5 mм EDTA, 5\% glycerol, $1.0 \mathrm{~mm}$ DTT, and protease inhibitor cocktail) and shaken for $2 \mathrm{~h}$ on ice at $200 \mathrm{rpm}$. Following centrifugation at $15000 \times \boldsymbol{g}$ for $5 \mathrm{~min}$, the supernatants of the samples were used as nuclear extracts. The protein concentration was determined using BCA reagents according to the manufacturer's instructions (Pierce).

Electrophoretic Mobility Shift Assay (EMSA) EMSA binding assays were performed with the NF- $\kappa$ B EMSA kit (Panomics) according to the manufacturer's instructions. The binding reaction was optimized in binding buffer containing 
$10 \%$ glycerol, $100 \mathrm{~mm} \mathrm{KCl}, 1.5 \mathrm{~mm} \mathrm{MgCl}_{2}$, and $0.3 \mathrm{~mm}$ EDTA. Briefly, $5 \mu \mathrm{g}$ nuclear extract was incubated with $10 \mathrm{ng}$ biotinylated double-stranded oligonucleotide probe containing the DNA-binding motif for NF- $\kappa \mathrm{B}\left(5^{\prime}\right.$-AGTTGAGGGGACTTTCCCAGGC-3') for $20 \mathrm{~min}$ at room temperature. The DNA-protein complexes were separated from nonbound oligonucleotides in a native $6 \%$ polyacrylamide gel in $0.5 \mathrm{X}$ Tris-borate-ethylenediamine tetraacetic acid (TBE) buffer at $4{ }^{\circ} \mathrm{C}$. These DNA-protein complexes were then transferred to nylon membranes (Biodyne $\mathrm{B}$ membrane) via standard electroblotting procedures for $30 \mathrm{~min}$ at $300 \mathrm{~mA}$ and $4^{\circ} \mathrm{C}$, followed by UV cross-linking. Biotinylated oligonucleotides were then detected using an HRP-conjugated streptavidin probe and were visualized via ECL. The chemiluminescence signal was imaged using a ChemiDoc XRS (Bio-Rad, Hercules, CA, U.S.A.) and was quantified using Quantity One software (Bio-Rad, Hercules, CA, U.S.A.).

Sodium Dodecyl Sulfate-Polyacrylamide Gel Electrophoresis (SDS-PAGE)/Immunoblot Analysis RAW264.7 cells were plated in $10-\mathrm{cm}$ culture plates and made quiescent at confluence by incubation in DMEM for $48 \mathrm{~h}$. Growtharrested cells $\left(1 \times 10^{6}\right.$ cells/well $)$ were incubated with LPS $(1.0 \mu \mathrm{g} / \mathrm{ml})$ at $37^{\circ} \mathrm{C}$ for $1 \mathrm{~h}$. When test drugs were used, they were added $2 \mathrm{~h}$ prior to the application of LPS. After treatment with LPS, the cells were rapidly washed with cold phosphate-buffered saline (PBS), scraped, and suspended in $400 \mu \mathrm{l}$ ice-cold RIPA buffer containing $20 \mathrm{~mm}$ Tris- $\mathrm{HCl}(\mathrm{pH}$ 7.5), $150 \mathrm{~mm} \mathrm{NaCl}, 2.5 \mathrm{~mm}$ sodium pyrophosphate, $1.0 \mathrm{~mm}$ beta-glycerophosphate, $1.0 \mathrm{~mm} \mathrm{Na}_{2} \mathrm{VO}_{4}, 1.0 \mathrm{~mm} \mathrm{Na} \mathrm{N}_{2}$ EDTA, $1.0 \mathrm{~mm}$ ethyleneglycol bis(2-aminoethylether)- $N, N, N^{\prime}, N^{\prime}$ tetraacetic acid (EGTA), 1\% (w/v) NP-40, 1.0\% (w/v) sodium deoxycholate, $1 \mu \mathrm{g} / \mathrm{ml}$ leupeptin, and $1.0 \mathrm{~mm}$ phenylmethylsulfonyl fluoride (PMSF). The cells were allowed to swell on ice for $10 \mathrm{~min}$ and were then vortexed vigorously for $10 \mathrm{~s}$. The homogenates were centrifuged at $14000 \times \boldsymbol{g}$ for $10 \mathrm{~min}$ at $4{ }^{\circ} \mathrm{C}$, yielding whole-cell extracts. The supernatants containing cytosolic proteins were collected and used for immunoblot analysis. Protein concentration was determined using BCA reagents according to the manufacturer's instructions. Proteins $(30 \mu \mathrm{g})$ were separated on a $5-10 \%$ gradient sodium dodecyl sulfate-polyacrylamaide gel and were electrotransferred to a nitrocellulose membrane (SDS-PAGE). The blot was incubated at room temperature with $1 \%(\mathrm{w} / \mathrm{v})$ BSA in TBS buffer (Tris- $\mathrm{HCl} 50 \mathrm{~mm}, \mathrm{NaCl} 150 \mathrm{~mm}, 0.05 \%$ (w/v), $\mathrm{pH} 8.0$ ) for $1 \mathrm{~h}$, then incubated with anti-COX-2, antiiNOS, anti-phopho-p42/p44 MAPK, anti-phospho-SAPK/ JNK, or anti-phospho-p38 MAPK, anti-phospho-IKK $\alpha / \beta$, or anti-phospho-I $\kappa \mathrm{B} \alpha$ antibodies at a dilution of $1: 1000$ in TTBS overnight at $4{ }^{\circ} \mathrm{C}$. After incubation with the appropriate HRP-conjugated anti-rabbit $\mathrm{IgG}$, the immunoreactive bands were visualized with enhanced chemiluminescence reagents (ECL, Intron Biotechnology). The chemiluminescence signal was imaged using a ChemiDoc XRS (Bio-Rad, Hercules, CA, U.S.A.) and was quantified using Quantity One software (Bio-Rad, Hercules, CA, U.S.A.).

Data Analysis All values are represented as means S.E. The statistical significance was calculated using ANOVA followed by the Bonferroni method. Differences were considered significant when the $p$ value was less than 0.05 . All statistics were performed using SigmaStat (SPSS Inc.).

\section{RESULTS}

Structures of DBLLs and Cytotoxicity to RAW264.7 Cells We first measured the cytotoxicities of DBLLs (Fig. 1A) to RAW264.7 cells using the MTT assay. DBLLs did not exhibit significant cytotoxicity in the concentration range of $0.1-10 \mu \mathrm{M}$ (Fig. 1B). Therefore, we choose $0.1,1$, and $10 \mu \mathrm{M}$ for the subsequent experiments.

Inhibitory Effects of DBLLs on iNOS Protein Expression Induced by LPS in RAW264.7 Cells LPS $(1.0 \mu \mathrm{g} / \mathrm{ml})$ significantly $(p<0.001)$ increased protein levels of iNOS in the cytosol of RAW264.7 cells by $261.35 \pm 2.14 \%$. Pre-treatment with dibenzylbutyrolactone lignans for $2 \mathrm{~h}$ at concentrations of $0.1-10 \mu \mathrm{M}$ significantly inhibited the expression of iNOS induced by LPS in macrophages in a concentrationdependent manner. Arctiin at $1.0 \mu \mathrm{M}$ significantly $(p<0.01)$ inhibited the expression of iNOS by $37.71 \pm 2.86 \%$, and arctigenin at $1.0 \mu \mathrm{M}$ significantly $(p<0.05)$ reduced the expression of iNOS by $32.51 \pm 4.28 \%$, whereas matairesinol at $10 \mu \mathrm{M}$ significantly $(p<0.05)$ reduced the expression of iNOS by $27.44 \pm 2.65 \%$. However, all dibenzylbutyrolactone lignans were less active than helenalin at $10 \mu \mathrm{M}$ (Fig. 2).

Inhibitory Effects of DBLLs on LPS-Induced COX-2 Expression in RAW264.7 Cells LPS treatment $(1.0 \mu \mathrm{g} / \mathrm{ml})$ significantly $(p<0.001)$ increased COX-2 protein levels compared with those of the vehicle control (281.20 $99.57 \%)$. Pre-treatment with DBLLs for $2 \mathrm{~h}$ at concentrations of $0.1-$ $10 \mu \mathrm{M}$ significantly reduced COX-2 protein expression. Arctiin at $0.1 \mu \mathrm{M}$ significantly $(p<0.01)$ inhibited the expression of COX-2 by $37.93 \pm 7.81 \%$, and arctigenin at $0.1 \mu \mathrm{M}$ significantly $(p<0.05)$ reduced the expression of COX-2 by $26.70 \pm 4.61 \%$, whereas matairesinol at $1.0 \mu \mathrm{M}$ significantly $(p<0.05)$ reduced the expression of COX-2 by $29.37 \pm$ $5.21 \%$. Arctiin was the most effective overall, with an effect nearly the same as that of helenalin at $10 \mu \mathrm{M}$ (Fig. 3).

Inhibitory Effects of DBLLs on LPS-Induced NO and PGE $_{2}$ Productions in RAW264.7 Cells To analyze the inflammatory products of iNOS and COX-2 enzymes, we used RAW264.7 cells, which can produce $\mathrm{NO}$ and $\mathrm{PGE}_{2}$ upon

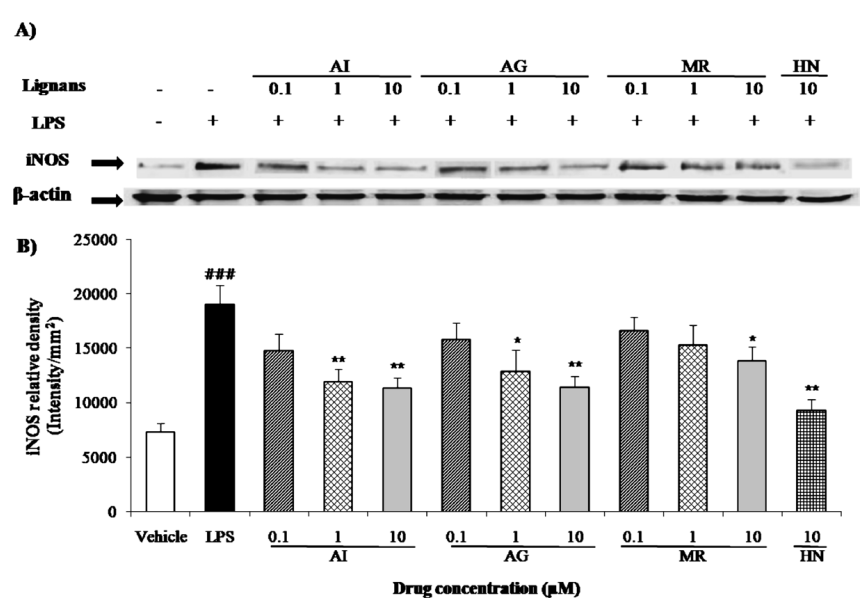

Fig. 2. Inhibitory Effects of DBLLs on iNOS Expression Induced by LPS

(A) Cells were pretreated with DBLLs $(0.1,1,10 \mu \mathrm{M})$ or helenalin $(10 \mu \mathrm{M})$ for $2 \mathrm{~h}$, then treated with LPS $(1 \mu \mathrm{g} / \mathrm{ml})$ for $1 \mathrm{~h}$ at $37^{\circ} \mathrm{C}$. The expression of iNOS was assessed using Western blot analysis. (B) iNOS relative density was analyzed using densitometry. Each value represents the mean \pm S.E. $(n=4)$. \#\# Represents $p<0.001$ compared to vehicle controls. Significant differences from LPS control are represented by $* p<0.05$, $* * p<0.01$. AI: arctiin, AG: arctigenin, MR: matairesinol, HN: helenalin. 
A)
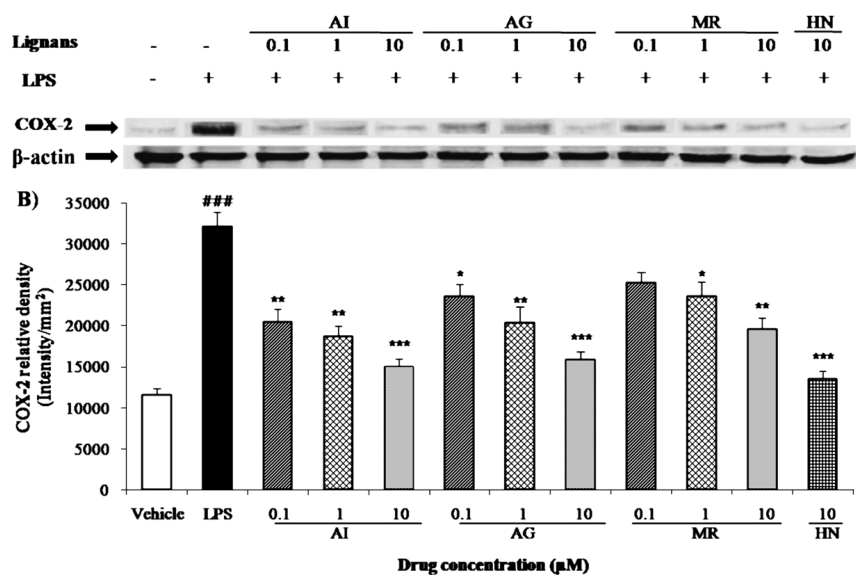

Fig. 3. Inhibitory Effects of DBLLs on the Expression of COX-2 Induced by LPS

(A) Cells were pretreated with DBLLs $(0.1,1,10 \mu \mathrm{M})$ or helenalin $(10 \mu \mathrm{M})$ for $2 \mathrm{~h}$, then treated with LPS $(1 \mu \mathrm{g} / \mathrm{ml})$ for $1 \mathrm{~h}$ at $37^{\circ} \mathrm{C}$. The expression of COX-2 was assessed using Western blot analysis. (B) COX-2 relative density was analyzed using densitometry. Each value represents the mean \pm S.E. $(n=4)$. \#册 Represents $p<0.001 \mathrm{com}-$ pared to vehicle controls. Significant differences from LPS control are represented by $* p<0.05, * * p<0.01$, and $* * * p<0.001$. AI: arctiin, AG: arctigenin, MR: matairesinol $\mathrm{HN}$ : helenalin.

stimulation with LPS. LPS $(1.0 \mu \mathrm{g} / \mathrm{ml})$ significantly $(p<$ 0.001 ) increased the productions of $\mathrm{NO}$ and $\mathrm{PGE}_{2}$ in RAW264.7 cells by $275.08 \pm 10.24 \%$ and $303.20 \pm 12.45 \%$, respectively. Pre-treatment with DBLLs for $2 \mathrm{~h}$ at concentrations of $0.1-10 \mu \mathrm{M}$ significantly inhibited the productions of $\mathrm{NO}$ and $\mathrm{PGE}_{2}$ induced by LPS in macrophages in a concentration-dependent manner. Arctiin at $1.0 \mu \mathrm{M}$ significantly $(p<0.01)$ inhibited the production of NO by $37.71 \pm 2.86 \%$, and arctigenin at $1.0 \mu \mathrm{M}$ significantly $(p<0.05)$ reduced the production of $\mathrm{NO}$ by $32.51 \pm 4.28 \%$, whereas matairesinol at $10 \mu \mathrm{M}$ significantly $(p<0.05)$ reduced the production of NO by $27.44 \pm 2.65 \%$. The inhibitory effects of DBLLs on NO production were seen to be the same as the patterns of reduction for iNOS expression (Fig. 4A). Arctiin and arctigenin at $0.1 \mu \mathrm{M}$ significantly $(p<0.05)$ reduced $\mathrm{PGE}_{2}$ production by $33.08 \pm 7.66 \%$ and $32.84 \pm 6.51 \%$, respectively, whereas matairesinol at $1.0 \mu \mathrm{M}$ significantly $(p<0.05)$ inhibited $\mathrm{PGE}_{2}$ production by $32.74 \pm 5.22 \%$. The inhibitory effects of DBLLs on $\mathrm{PGE}_{2}$ production showed the same patterns as those for the reduction of COX-2 expression (Fig. 4B).

Inhibitory Effects of DBLLs on LPS-Induced NF- $\kappa \mathrm{B}$ DNA Binding Activity in RAW264.7 Cells Potent activation of NF- $\kappa \mathrm{B}$ was induced by LPS in RAW264.7 cells. LPS $(1.0 \mu \mathrm{g} / \mathrm{ml})$ significantly $(p<0.001)$ increased the relative density of NF- $\kappa$ B DNA binding activity by $357.14 \pm 17.13 \%$. Nuclear extracts from LPS-stimulated cells pre-treated with DBLLs $(0.1,1.0,10 \mu \mathrm{M})$ for $2 \mathrm{~h}$ demonstrated inhibition of the induction of specific NF- $\kappa \mathrm{B}$ binding activity in a concentration-dependent manner. Artiin and arctigenin at $1.0 \mu \mathrm{M}$ significantly $(p<0.05)$ reduced NF- $\kappa \mathrm{B}$ DNA binding by $44.85 \pm 6.67 \%$ and $44.16 \pm 6.61 \%$, respectively, whereas matairesinol at $10 \mu \mathrm{M}$ significantly $(p<0.05)$ inhibited NF$\kappa \mathrm{B}$ DNA binding by $44.79 \pm 5.62 \%$. Arctiin was the most effective overall, with an effect nearly the same as that of helenalin at $10 \mu \mathrm{M}$ (Fig. 5).

Inhibitory Effect of DBLLs on IKB Phosphorylation LPS $(1.0 \mu \mathrm{g} / \mathrm{ml})$ significantly $(p<0.001)$ increased the distri-
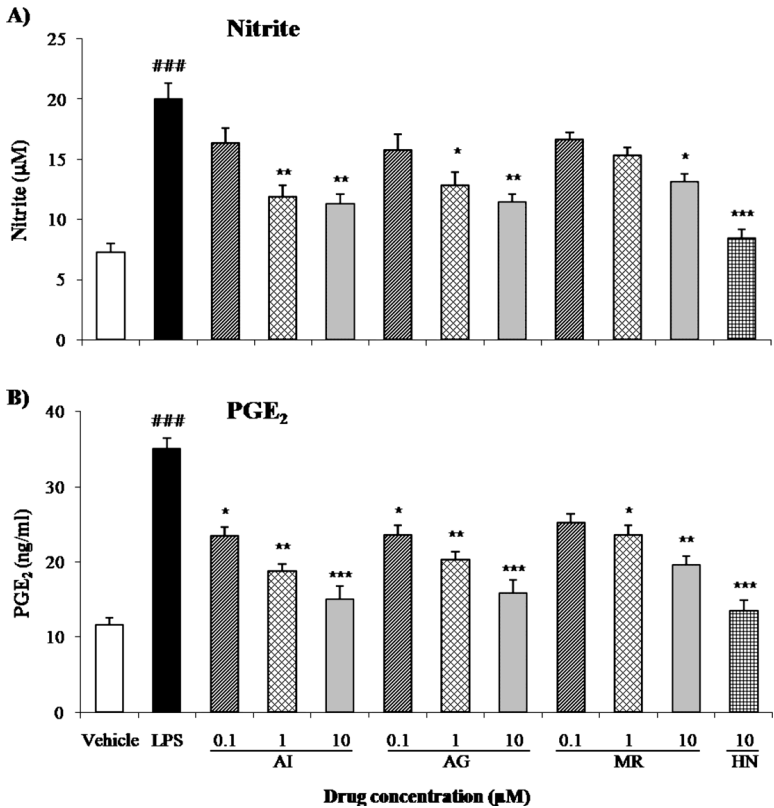

Fig. 4. Inhibitory Effects of DBLLs on LPS-Induced NO and PGE 2 Productions in RAW264.7 Cells

(A) Cell were pre-incubated with DBLLs $(0.1,1,10 \mu \mathrm{M})$ or helenalin $(10 \mu \mathrm{M})$ for $2 \mathrm{~h}$, then treated with LPS $(1 \mu \mathrm{g} / \mathrm{ml})$ for $1 \mathrm{~h}$ at $37^{\circ} \mathrm{C}$. NO production was analyzed using Greiss reagent. (B) DBLLs were treated as described above. $\mathrm{PGE}_{2}$ production was analyzed using a PGE 2 EIA kit. Each value represents the mean \pm S.E. $(n=4)$. \#\# Represents $p<0.001$ compared to vehicle controls. Significant differences from LPS control are represented by $* p<0.05, * * p<0.01$, and $* * * p<0.001$. AI: arctiin, AG: arctigenin, MR: matairesinol, $\mathrm{HN}$ : helenalin.

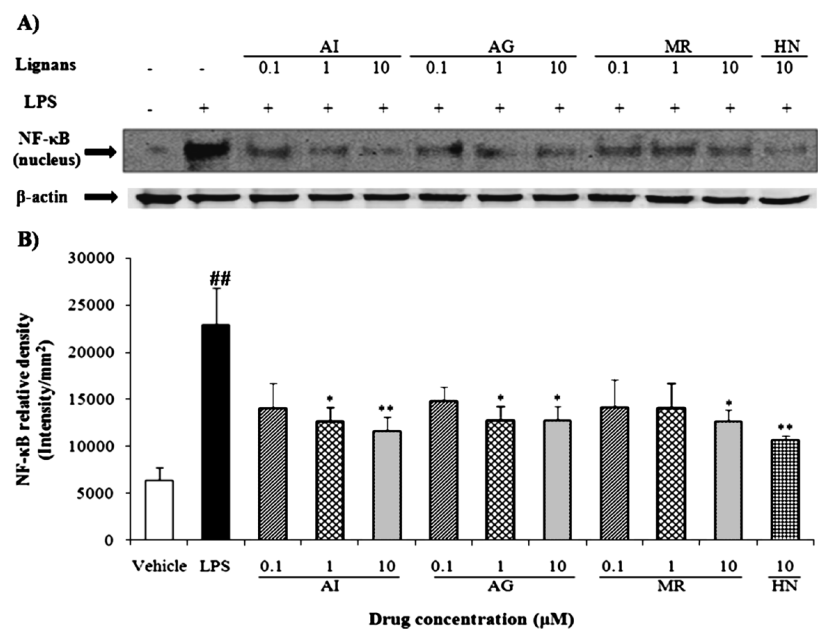

Fig. 5. Inhibitory Effects of DBLLs on LPS-Induced NF- $\kappa$ B DNA Binding Activity in RAW264.7 Cells

(A) RAW264.7 cells were pre-incubated with DBLLs $(0.1,1,10 \mu \mathrm{M})$ or helenalin $(10 \mu \mathrm{M})$ for $2 \mathrm{~h}$, then treated with LPS $(1 \mu \mathrm{g} / \mathrm{ml})$ for $1 \mathrm{~h}$ at $37^{\circ} \mathrm{C}$. After incubation, nuclear extracts were prepared from the cells and analyzed using EMSA for activated NF$\kappa \mathrm{B}$ using radiolabeled oligonucleotide probes. (B) The relative density of NF- $\kappa \mathrm{B}$ DNA binding was analyzed using densitometry. Each value represents the mean \pm S.E. $(n=4)$ \#\#Represents $p<0.001$ compared to vehicle controls. Significant differences from LPS control are represented by $* p<0.05$ and $* * p<0.01$. AI: arctiin, AG: arctigenin, MR: matairesinol, $\mathrm{HN}$ : helenalin.

bution of phospho-I $\kappa \mathrm{B} \alpha$ in the cytosol of RAW264.7 cells by $277.77 \pm 5.49 \%$. Pre-treatment with dibenzylbutyrolactone lignans for $2 \mathrm{~h}$ at concentrations of $0.1-10 \mu \mathrm{M}$ significantly inhibited the phosphorylation of $\mathrm{I} \kappa \mathrm{B}$ induced by LPS in macrophages in a concentration-dependent manner. Arctiin at $0.1 \mu \mathrm{M}$ significantly $(p<0.05)$ inhibited the phosphorylation of I $\kappa$ B by $20.58 \pm 3.86 \%$, and arctigenin at $1.0 \mu \mathrm{M}$ signif- 
A)

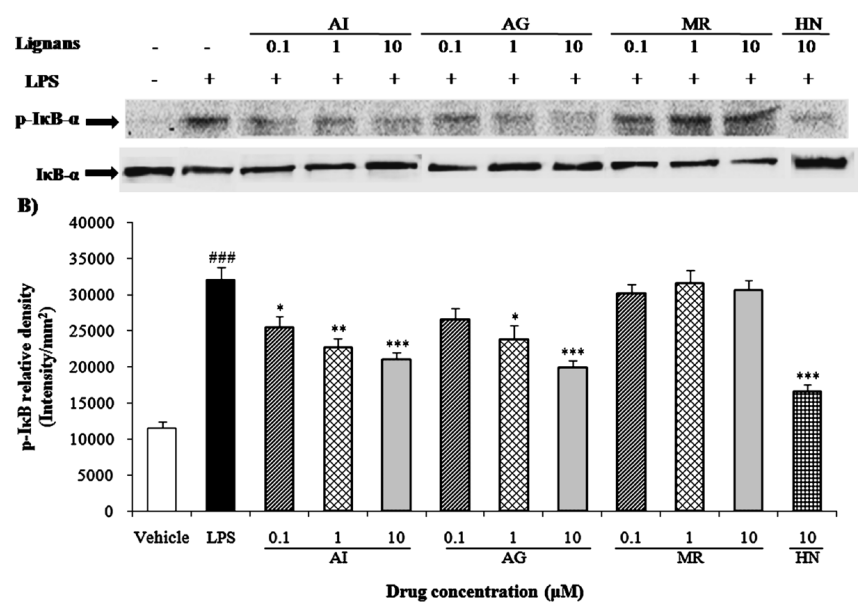

Fig. 6. Inhibitory Effects of DBLLs on $\mathrm{I} \kappa \mathrm{B}$ Phosphorylation in RAW264.7 Cells

(A) Cells were pretreated with DBLLs $(0.1,1,10 \mu \mathrm{M})$ or helenalin $(10 \mu \mathrm{M})$ for $2 \mathrm{~h}$, then treated with LPS $(1 \mu \mathrm{g} / \mathrm{ml})$ for $1 \mathrm{~h}$ at $37^{\circ} \mathrm{C}$. The phosphorylation of I $\kappa \mathrm{B}-\alpha$ was assessed using Western blot analysis. (B) p-I $\kappa$ B relative density was analyzed using densitometry. Each value represents the mean \pm S.E. $(n=4)$. \#\# Represents $p<0.001 \mathrm{com}$ pared to vehicle controls. Significant differences from LPS control are represented by $* p<0.05, * * p<0.01$, and $* * * p<0.001$. AI: arctiin, AG: arctigenin, MR: matairesinol, $\mathrm{HN}$ : helenalin.

icantly $(p<0.05)$ reduced the phosphorylation of $\mathrm{I} \kappa \mathrm{B}$ by $25.99 \pm 6.18 \%$. Matairesinol did not have a significant effect. All three DBLLs were less active than helenalin at $10 \mu \mathrm{M}$ (Fig. 6).

Inhibitory Effects of DBLLs on IKK Phosphorylation LPS $(1.0 \mu \mathrm{g} / \mathrm{ml})$ significantly $(p<0.001)$ increased the protein levels of phospho-IKK $\alpha / \beta$ in the cytosol of RAW264.7 cells by $322.58 \pm 7.04 \%$. Pre-treatment with dibenzylbutyrolactone lignans at $0.1-10 \mu \mathrm{M}$ for $2 \mathrm{~h}$ significantly $(p<0.05)$ reduced the phosphorylation of IKK $\alpha / \beta$ in the cytosol. Artiin and matairesinol at $1.0 \mu \mathrm{M}$ significantly $(p<0.01)$ inhibited the phosphorylation of $\operatorname{IKK} \alpha / \beta$ (by $38.80 \pm 6.64 \%$ and $38.33 \pm 6.65 \%$, respectively), whereas arctigenin at $10 \mu \mathrm{M}$ significantly $(p<0.01)$ reduced the phosphorylation of IKK $\alpha / \beta$ by $38.57 \pm 8.14 \%$. However, all DBLLs were less active than helenalin at $10 \mu \mathrm{M}$ (Fig. 7).

Inhibitory Effects of DBLLs on LPS-Induced Activation of MAP Kinase in RAW264.7 Cells LPS $(1.0 \mu \mathrm{g} / \mathrm{ml})$ strongly increased the protein levels of phospho-SAPK/JNK, p38, and ERK1/2 in RAW264.7 cells by $240.74 \pm 9.85 \%$, $259.17 \pm 7.41 \%$ and $244.35 \pm 4.78 \%$, respectively (Fig. 8). Pre-treatment with dibenzylbutyrolactone lignans at $0.1-$ $10 \mu \mathrm{M}$ significantly inhibited the level of phospho-MAPK protein. Arctiin inhibited activations of all three MAP kinases (SAPK/JNK, p38 and ERK1/2) in dose-dependent manners. Arctigenin exhibited inhibitory effects on SAPK/ JNK and ERK1/2, but not on p38 MAPK, in dose-dependent manners. Matairesinol reduced the activation of only p38 MAP kinase in a dose-dependent manner. At most concentrations, DBLLs were less active than were the specific inhibitors of MAPKs, including SP600125 $(10 \mu \mathrm{M})$, SB203580 $(10 \mu \mathrm{M})$, and PD98059 $(50 \mu \mathrm{M})$ (Fig. 8).

\section{DISCUSSION}

We previously reported that DBLLs from $F$. koreana fruits
A)

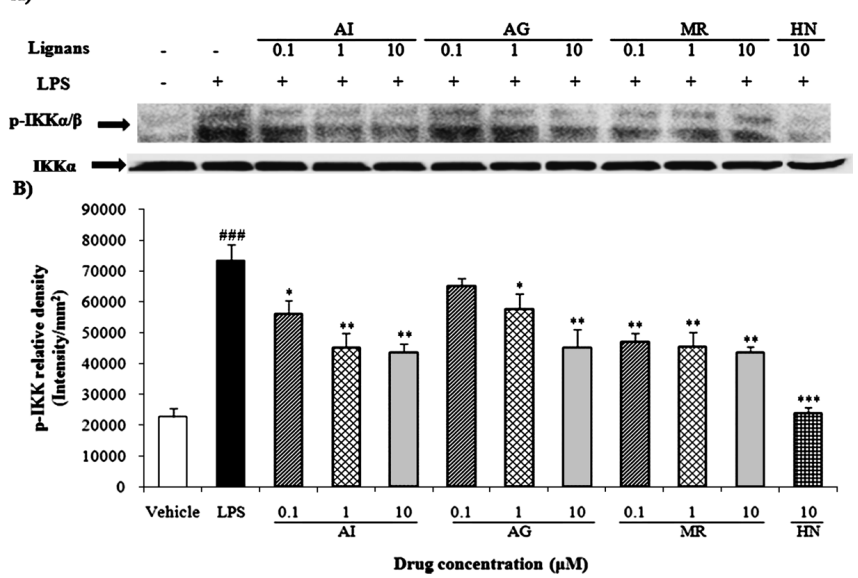

Fig. 7. Inhibitory Effects of DBLLs on IKK Phosphorylation in RAW264.7 Cells

(A) Cells were pretreated with dibenzylbutyrolactone lignans $(0.1,1,10 \mu \mathrm{M})$ or helenalin $(10 \mu \mathrm{M})$ for $2 \mathrm{~h}$, then treated with LPS $(1 \mu \mathrm{g} / \mathrm{ml})$ for $1 \mathrm{~h}$ at $37^{\circ} \mathrm{C}$. The phosphorylation of IKK was analyzed using Western blot analysis. (B) The relative density of IKK $\alpha / \beta$ phosphorylation was analyzed using densitometry. Each value represents the mean \pm S.E. $(n=4)$. \#\# Represents $p<0.001$ compared to vehicle controls. Significant differences from LPS control are represented by $* p<0.05$, $* * p<0.01$, and $* * * p<0.001$. AI: arctiin, AG: arctigenin, MR: matairesinol, HN: helenalin.

have anti-inflammatory, antioxidant, and analgesic effects. ${ }^{1)}$ In addition, they have inhibitory effects on AA-induced ear edema, LPS-induced $\mathrm{PGE}_{2}$ levels in neutrophils and monocytes, IL-8-induced neutrophil chemotaxis, as well as antiasthmatic effects ${ }^{2)}$ both in vivo and in vitro. In this study, our findings provided a molecular basis for the modes of action of dietary, biochemically-active compounds in the prevention of inflammatory diseases. DBLLs markedly inhibited the expressions of iNOS and COX-2, the productions of $\mathrm{NO}$ and $\mathrm{PGE}_{2}$ induced by LPS (Figs. 2-4), as well as LPS-induced activations of NF- $\kappa \mathrm{B}$ and MAPKs in a concentrationdependent manner (Figs. 5, 8) in RAW264.7 cells. On the other hand, NF- $\kappa$ B and MAPKs were not induced by DBLLs without LPS stimulation. To identify the mechanism of their inhibitory effects on iNOS and COX-2 via the inhibition of NF- $\kappa \mathrm{B}$ activation, we examined the phosphorylation of $\mathrm{I} \kappa \mathrm{B}$, a required step for NF- $\kappa \mathrm{B}$ activation. Immunoblot analysis showed that inhibition of NF- $\kappa \mathrm{B}$ activity by DBLLs may result from the inhibition of $\mathrm{I} \kappa \mathrm{B} \alpha$ phosphorylation (Fig. 6). Under un-stimulated conditions, NF- $\kappa \mathrm{B}$ is sequestered within the cytosol as an inactive complex bound to $\mathrm{I} \kappa \mathrm{B}$. After stimulation of NF- $\kappa \mathrm{B}$ by a variety of stimuli (such as LPS and inflammatory cytokines), I $\kappa \mathrm{B}$ is phosphorylated by the I $\kappa \mathrm{B}$ kinases IKK $\alpha$ and $\operatorname{IKK} \beta$, and rapid degradation of the $\mathrm{I} \kappa \mathrm{B}$ subunit by proteosomes occurs. ${ }^{22}$ Velasco et al. reported that $\mathrm{I} \kappa \mathrm{B} \alpha$ levels decreased at $40 \mathrm{~min}$ and increased at $3 \mathrm{~h}$ after stimulation with LPS. ${ }^{23}$ However, our experiment showed that $\mathrm{I} \kappa \mathrm{B} \alpha$ levels moderately increased at $1 \mathrm{~h}$ after stimulation with LPS. NF- $\kappa \mathrm{B}$ is then released from $\mathrm{I} \kappa \mathrm{B}$ and translocates into the nucleus. In the nucleus, NF- $\kappa \mathrm{B}$ dimers bind to target DNA elements and activate the transcriptions of genes encoding proteins involved in immune and inflammation responses, as well as cell growth control. ${ }^{24)}$ Furthermore, we investigated the ability of DBLLs to inhibit the phosphorylation of IKK, which is thought to mediate the phosphorylation of $\mathrm{I} \kappa \mathrm{B} \alpha$ at two conserved serine residues in the N-terminal domain of $\mathrm{I} \kappa \mathrm{B}$. The induction of phospho- 


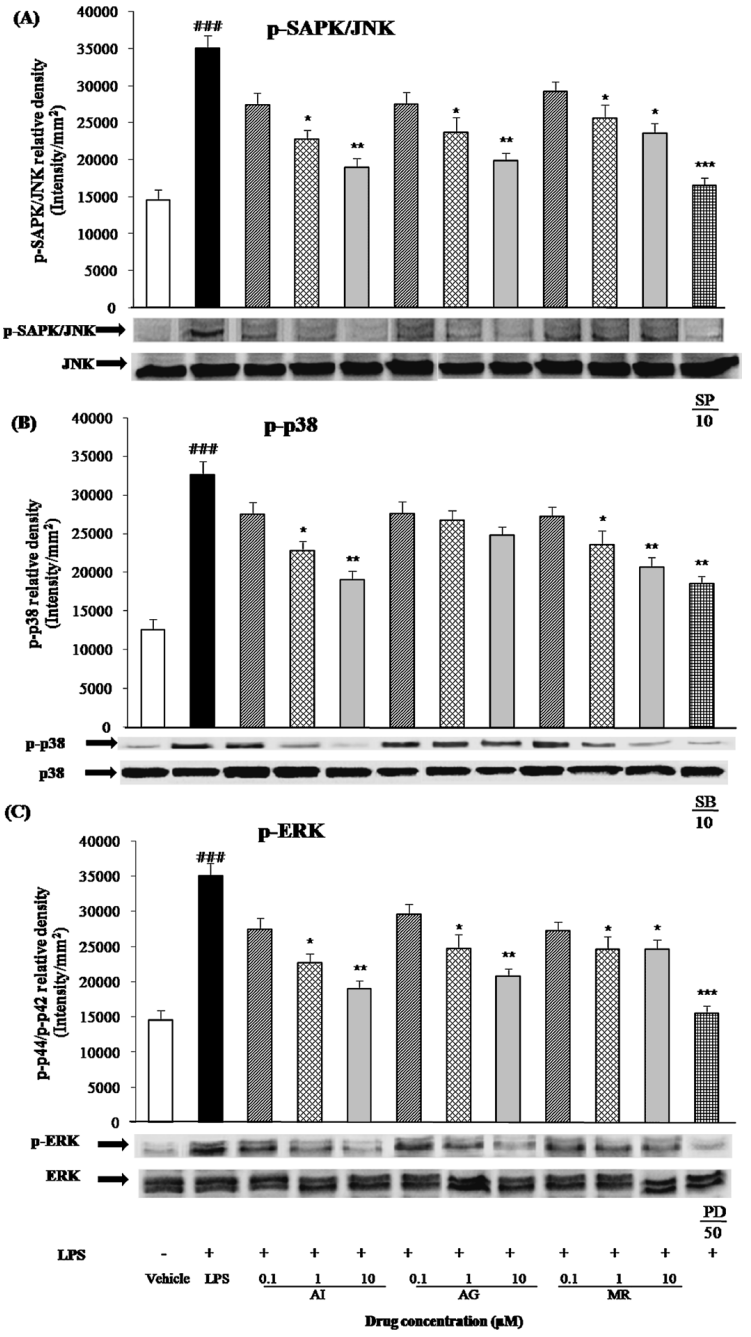

Fig. 8. Effects of DBLLs on MAP Kinase Phosphorylation in RAW264.7 Cells

Cells were pretreated with dibenzylbutyrolactone lignans $(0.1,1,10 \mu \mathrm{M})$ for $2 \mathrm{~h}$, then treated with LPS $(1 \mu \mathrm{g} / \mathrm{ml})$ for $1 \mathrm{~h}$ at $37^{\circ} \mathrm{C}$. Total cellular proteins were prepared for Western blot analysis of phospho-MAPKs proteins using specific anti-phospho MAPKs antibodies. p-SAPK/JNK(A), p-p38(B) and p-ERK1/2(C) relative densities were analyzed using densitometry. Each value representss the mean \pm S.E. $(n=4)$. \#\# Represents $p<0.001$ compared to vehicle controls. Significant differences from LPS control are represented by $* p<0.05, * * p<0.01$, and $* * * p<0.001$. AI: arctiin, AG: arctigenin, MR: matairesinol, HN: helenalin. SP; SP600125, SB; SB203580, PD; PD98059.

IKK $\alpha / \beta$ protein levels by LPS was significantly decreased by DBLLs. These results indicate that the inhibitory effects of DBLLs on iNOS and COX-2 via NF- $\kappa$ B activation result from inhibition of $\mathrm{I} \kappa \mathrm{B}$ degradation via the modulation of $\mathrm{IKK} \alpha / \beta$.

The MAP kinases play a critical role in the regulation of cell growth and differentiation and in cellular responses to cytokines and stresses. ${ }^{25}$ Moreover, MAP kinases are involved in the LPS-induced cytokine expression signaling pathway. Recently, it was found that JNK may be associated with the cRel subunit of NF- $\kappa \mathrm{B}$ and may directly enhance $\mathrm{NF}-\kappa \mathrm{B}$ activation in the yeast two-hybrid system. ${ }^{26)}$ In the present study, we also investigated the effects of DBLLs on LPS-induced MAP kinase phosphorylation in RAW264.7 cells. Pre-treatment with DBLLs was found to significantly inhibit LPS-induced SAPK/JNK, p38, and ERK1/2 phosphorylation, suggesting that $\mathrm{SAPK} / \mathrm{JNK}$, p38, and ERK1/2 are involved in the inhibition of LPS-stimulated NF- $\kappa \mathrm{B}$ binding by DBLLs in RAW264.7 cells. These results are in agreement with those of Cho's report which showed that arctigenin can suppress the expressions of LPS-induced SAPK/JNK, $\mathrm{p} 38$, and $\mathrm{p} 42 / 44$ proteins in murine macrophages. ${ }^{27)}$ In addition, these results show that three DBLLs, matairesinol, arctigenin $\left(\mathrm{R}_{2}\right.$-methoxy matairesinol), and arctiin $\left(\mathrm{R}_{1}\right.$-glycosyl arctigenin), had different effects on the activations of MAPK proteins. Arctiin, a glycoside of arctigenin, was the most active and had the greatest dose-dependent inhibition of the activations of all three MAP kinases (SAPK/JNK, p38, and ERK1/2), whereas arctigenin had dose-dependent inhibitory effects on SAPK/JNK and ERK1/2 but not on p38 MAPK. Matairesinol (non- $\mathrm{R}_{1}$-glycosyl radical) reduced the activation of only p38 MAP kinase in a dose-dependent manner. Therefore, $\mathrm{R}_{1}$-glycosyl radical lignans were shown to be very important in the inhibition of MAP kinase activation.

In summary, our results revealed that the anti-inflammatory effects of DBLLs through the inhibition of iNOS and COX -2 are associated with NF- $\kappa \mathrm{B}$ inactivation and the suppression of NF- $\kappa \mathrm{B}$-regulated proteins. It is well known that LPS induces NF- $\kappa \mathrm{B}$ activation through the MAP kinase family. ${ }^{28,29)}$ DBLLs have the potential to inhibit the LPS-induced phosphorylations of SAPK/JNK, p38, and ERK1/2, suggesting that DBLLs exhibit potent anti-inflammatory activity through the specific inhibitions of MAPKs activation. Furthermore, DBLLs are non-toxic in RAW264.7 cells, which is consistent with the results of other reports, ${ }^{30)}$ and arctiin had nearly the same activity as helenalin at $10 \mu \mathrm{M}$.

\section{REFERENCES}

1) Kang H. S., Lee J. Y., Kim C. J., J. Ethnopharmacol., 116, 305-312 (2008).

2) Lee J. H., Lee J. Y., Kim C. J., Phytother. Res., DOI: 10.1002/ptr. 3273 (2010).

3) Nam N., Mini-Rev. Med. Chem., 6, 945-951 (2006).

4) Nishibe S., Yakugaku Zasshi, 122, 363-379 (2002).

5) Lee J. Y., Moon H., Kim C. J., Biol. Pharm. Bull., 33, 230-237 (2010).

6) Awele S., Lu J., Kalauni S. K., Tezuka Y., Kadola S., Esumi H., Cancer Res., 66, 1751-1757 (2006).

7) Matsumoto T., Hosono-Nishiyama K., Yamada H., Planta Med., 72, $276-278$ (2006).

8) Chen F., Castranova V., Shi X., Demers L. M., Clin. Chem., 45, 7-17 (1999).

9) Chiang Y., Lo C., Chen Y., Wang S., Yang N., Kuo Y., Shyur L., Br. J. Pharmacol., 146, 352-363 (2005).

10) Fujiwara N., Kobayashi K., Curr. Drug Targets Inflamm. Allergy, 4, $281-286$ (2005).

11) Au R. Y., Al-Talib T. K., Au A. Y., Phan P. V., Frondoza C. G., Osteoarthr. Cartil., 15, 1249-1255 (2007).

12) Beyaert R., "Nuclear Factor $\kappa \mathrm{B}$ : Regulation and Role in Disease," Kluwer Academic Publishers, Netherlands, 2003.

13) Lyss G., Knorre A., Schmidt T. J., Pahl H. L., Merfort I., J. Biol. Chem., 273, 33508-33516 (1998).

14) Bennet B. L., Sasaki D. T., Murray B. W., O’Leary E. C., Sakata S. T., $\mathrm{Xu}$ W., Leisten J. C., Motiwala A., Pierce S., Satoh Y., Bhagwat S. S., Manning A. M., Anderson D. W., Proc. Natl. Acad. Sci. U.S.A., 98, 13681-13686 (2001).

15) Borsch-Haubold A. G., Pasquet S., Watson S. P., J. Biol. Chem., 273 , 28766-28772 (1998).

16) Alessi D. R., Cuenda A., Cohen P., J. Biol. Chem., 270, 27489-27494 (1995).

17) Jang Y. P., Kim S. R., Kim Y. C., Planta Med., 67, 470-472 (2001).

18) Eich E., Pertz H., Kaloga M., Schulz J., Fesen M. R., Mazumder A., Pommier Y., J. Med. Chem., 39, 86-95 (1996).

19) Shoeb M., MacManus S. M., Kumarasamy Y., Jaspars M., Nahar L., 
Jaspers M., Nahar L., Thoo-Lin P. K., Nazemiyeh H., Sarker S. D., Phytochemistry, 67, 2370-2375 (2006).

20) Kim M. R., Moon H. T., Lee D. G., Woo E. R., Arch. Pharm. Res., 30, 425-430 (2007).

21) Denizot F., Lang R., J. Immunol. Methods, 89, 271-277 (1986).

22) Baeuerle P. A., Cell, 95, 729-731 (1998).

23) Velasco M., Diaz-Guerra M. J. M., Martin-Sanz P., Alvarez A., Bosca L., J. Biol. Chem., 272, 23025-23030 (1997).

24) Balwin A. S., Annu. Rev. Immunol., 14, 649-683 (1996).

25) Vanden Berghe W., Plaisance S., Boone E., De Bosseher K., Lienhard
Schmiitz M., Fiers W., Hageman G., J. Biol. Chem., 273, 29400 29409 (1998).

26) Meyer C. F., Wang X., Chang C., Templeton D., Tan T. H., J. Biol. Chem., 271, 8971-8976 (1996).

27) Cho M. K., Jang Y. P., Kim Y. C., Kim S. G., Int. Immunopharmacol., 4, 1419-1429 (2004).

28) Doyle S. L., O’Neill L. A., Biochem. Pharmacol., 72, 1102-1113 (2006).

29) Kawai T., Akira S., Cell Death Differ., 13, 816-225 (2006).

30) Zhao F., Wang L., Liu K., J. Ethnopharmacol., 122, 457-462 (2009). 